\title{
Identification of an
}

\section{In Vitro Ribonucleoprotein Complex Between a Viroid RNA and a Phloem Protein from Cucumber Plants}

\author{
Gustavo Gómez and Vicente Pallás \\ Instituto de Biología Molecular y Celular de Plantas, Universidad Politécnica de Valencia-CSIC, Av. de los \\ Naranjos s/n, 46022 Valencia-Spain \\ Submitted 11 December 2000; Accepted 19 March 2001.
}

\begin{abstract}
We used the interaction of Hop stunt viroid (HSVd) and cucumber plants to investigate the involvement of phloem proteins in the systemic transport of RNA molecules. A ribonucleoprotein complex, stable even at high salt and temperature conditions, was detected in vitro between HSVd-RNA and the phloem exudate obtained from sectioned internodes from cucumber plants. The phloem protein 2 was recovered from this ribonucleoprotein complex and its RNA-binding properties as demonstrated by gel retardation analysis. The involvement of this protein in the movement of RNAs in cucumber is discussed.
\end{abstract}

A large body of evidence has revealed recently that plants evolved an endogenous transport system for the translocation of macromolecules in order to integrate physiological processes (Lucas and Wolf 1999; Thompson and Schulz 1999). Recent reports have shown that RNAs also can move long distances through vasculature (Citovsky and Zambryski 2000; Jorgensen et al. 1998; Palauqui et al. 1997; XoconostleCazares et al. 1999). The form by which RNA molecules travel long distances from their site of synthesis to different parts of the plants, however, is poorly understood (Citovsky and Zambryski 2000; Jorgensen et al. 1998). We reasoned that the interaction between Hop stunt viroid (HSVd) and cucumber plants could be a good model system to identify host proteins that may be involved in the systemic transport of RNAs. Plants of different genera of Cucurbitaceae spp. have a remarkably high concentration of $110 \mathrm{mg}$ of phloem proteins per $\mathrm{ml}$ (Eschrich et al. 1973), and phloem sap can easily be obtained as an exudate from sectioned internodes. Viroids, however, are small RNA pathogens of higher plants that do not code for any protein (Diener 1991; Flores et al. 1997), and their movement must be mediated by preexisting host proteins. Microinjection experiments have shown that viroids move from cell to cell through plasmodesmata (Ding et al. 1997). Long-distance movement of viroids occurs as in most plant viruses, by translocation in the phloem (Palukaitis 1987).

Corresponding author: V. Pallás; Fax: +34 96387 7859;

E-mail: vpallas@ibmcp.upv.es
The phloem exudate from Cucurbitaceae spp. contains more than 200 proteins. The most prominent polypeptides are the phloem protein 1 (PP1), a polypeptide of $96 \mathrm{kDa}$, and phloem protein 2 (PP2), a dimeric lectin of $48 \mathrm{kDa}$ that, upon sodium dodecyl sulfate-polyacrylamide gel electrophoresis (SDS-PAGE), predominantly occurs as a $24-$ to $26-\mathrm{kDa}$ monomer (Esau and Cronshaw 1967; Read and Northcote 1983a). The function of both proteins in the plant is not understood, although recent evidence indicates that both have the ability to translocate in the phloem (Golecki et al. 1998; Golecki et al. 1999).

The phloem exudate was collected from the sectioned internodes of HSVd- and mock-inoculated cucumber plants diluted immediately with 1 volume of binding buffer $(10 \mathrm{mM}$ Tris$\mathrm{HCl}, \mathrm{pH}$ 8.0; 1 mM EDTA; $100 \mathrm{mM} \mathrm{NaCl}, 5 \mathrm{U}$ HrpI RNase inhibitor [Amersham Pharmacia Biotech, Piscataway, NJ, U.S.A.]; $10 \%$ glycerol) in the presence of $20 \mathrm{mM}$ dithiothreitol to prevent oxidation. Nucleic acids were extracted from phloem exudate, as described previously (Pallás et al. 1987). The presence of the viroid was analyzed by reverse transcription-polymerase chain reaction amplification with the oligonucleotides VP 98 and VP 99 (Astruc et al. 1996). A band of the expected size was amplified from extracts of infected plants, confirming that HSVd was present in the phloem (data not shown).

In order to obtain evidence of an interaction of viroid RNA with phloem protein, monomeric transcripts of $(+) \mathrm{HSVd}-\mathrm{RNA}$ were incubated with different dilutions of phloem exudate in binding buffer, as described previously (Marcos et al. 1999). The samples were electrophoresed in agarose gels, electrotransferred to nylon membranes, and hybridized with a digoxigenin-labeled HSVd(-) riboprobe (Pallás et al. 1998). The phloem exudate contains factors capable of interacting with the HSVd-RNA, as shown by the formation of a complex detectable at 1/800 dilution of phloem exudate, and could not enter into the electrophoretic gel (Fig. 1A, left panel, lane 3). At 1/200 dilution, the free RNA band disappeared (Fig. 1A, left panel, lane 5). The absence of intermediate complexes can be explained by a cooperative nature of the interaction or, alternatively, by the binding of the RNA to several proteins or to a single protein monomer in a protein aggregate, as noted 
previously (Carey 1991). Treatment with proteinase K clearly abolished the formation of the complex, thus indicating the proteinaceous nature of the phloem component(s) interacting with the HSVd-RNA (data not shown). Stability of the protein-RNA complex, with respect to salt concentration, is often the criterion used to evaluate the strength of a protein-RNA association (Carey 1991). Thus, the RNA binding assays also were conducted at different salt concentrations. Binding was stable up to $800 \mathrm{mM} \mathrm{NaCl}$ (Fig. 1A, center panel), suggesting that phloem exudate-RNA complex is not solely the result of the electrostatic interactions between the nucleic acids and basic proteins. In addition, the complex was resistant up to $42^{\circ} \mathrm{C}$ and began to disappear above $55^{\circ} \mathrm{C}$ (Fig. 1A, right panel). When two other viroid RNAs, Citrus exocortis viroid and Avocado sunblotch viroid (Fig. 1B), and a RNA made by transcribing plasmid DNA (not shown) were used, the formation of a similar ribonucleoprotein complex was observed, indicating that PP2 has the capability to bind RNA molecules of a different nature. Competition assays, however, revealed that cDNAs containing sequences of viroid or plasmid origin do not compete for the complex formation (data not shown). Taken together, the results described above indicate that a protein component of the phloem exudate has the capability to bind ssRNA molecules in a sequence-nonspecific manner.

To identify the phloem protein(s) present in the ribonucleoprotein complex, in vitro-transcribed ${ }^{32} \mathrm{P}$-labeled $(+) \mathrm{HSVd}-$ RNA was incubated with phloem exudate, UV cross-linked, and analyzed by SDS-PAGE. The ribonucleoprotein complex was visualized by autoradiography, and the corresponding gel piece was excised. The gel fragment containing the complex was dehydrated, digested with RNase- $\mathrm{T}_{1}$, and electroeluted. Electroelution products were subjected to electrophoresis in a polyacrylamide gel and silver stained. The same process was carried out in parallel with phloem exudate incubated without HSVd-RNA as a control. A 24- to 26-kDa band was recovered differentially from the phloem exudate incubated with HSVdRNA but not from the control (Fig. 2, lanes 1 and 2, respectively). Two prominent bands corresponding to the RNase $\mathrm{T}_{1}$

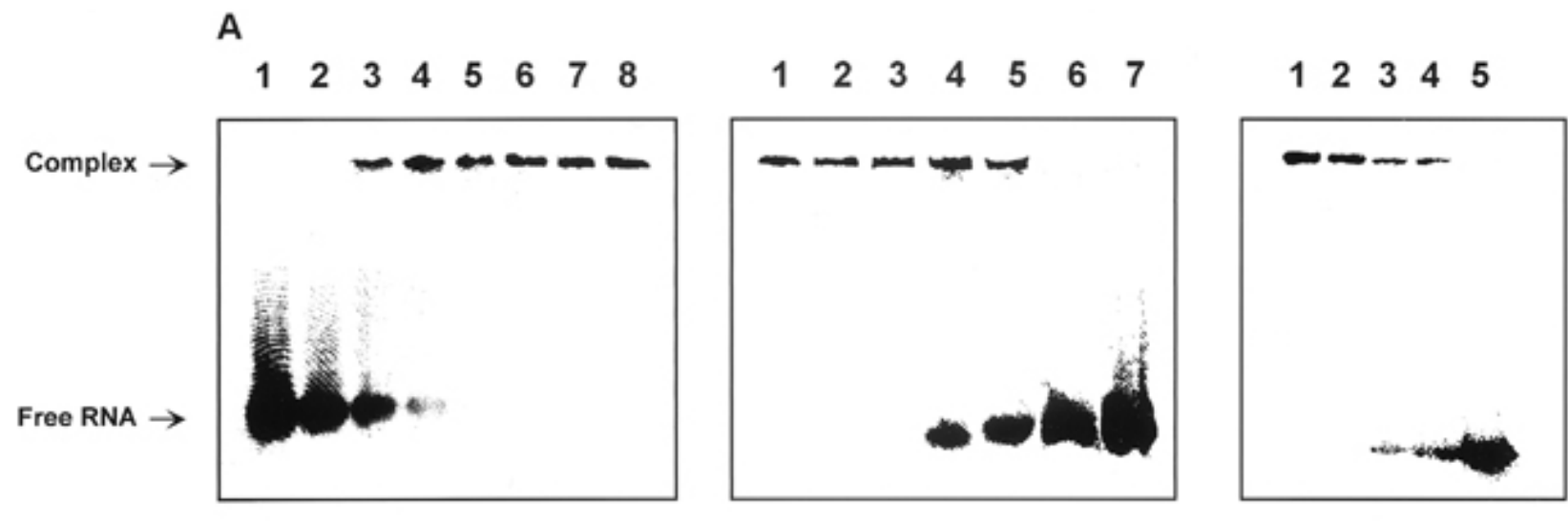

B

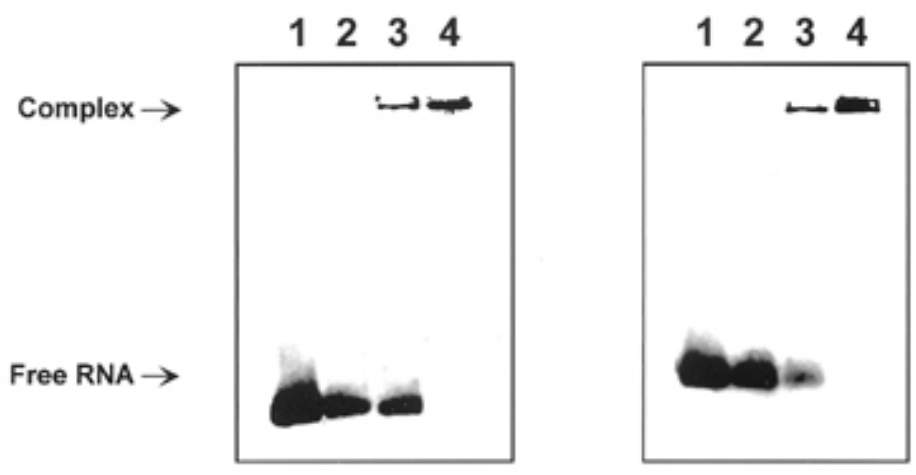

Fig. 1. A, Gel retardation analysis with Hop stunt viroid (HSVd) RNA and different phloem exudate dilutions obtained from cucumber internodes. Left panel: Monomeric transcripts of (+)HSVd RNA ( $5 \mathrm{ng}$ ) were incubated (30 min on ice), with $5 \mu \mathrm{l}$ of several dilutions of phloem exudate, in $15 \mu \mathrm{l}$ of final volume of binding buffer (BB) (10 mM Tris-HCl, pH 8.0; 1 mM EDTA; $100 \mathrm{mM} \mathrm{NaCl} ; 5$ units of HrpI RNase inhibitor [Amersham Pharmacia Biotech, Piscataway, NJ, U.S.A.]; $10 \%$ glycerol). Following incubation, $2 \mu \mathrm{l}$ of tracking dye were added and the samples were electrophoresed through $0.8 \%$ agarose in TAE buffer, transferred to nylon membranes, hybridized with digoxigenin-labeled HSVd riboprobes, and detected with anti-dig antibody APconjugate. Lane 1: Free HSVd RNA. Lanes 2-8: HSVd-RNA incubated with dilutions 1/1600, 1/800, 1/400, 1/200, 1/100, 1/50, and 1/25 of the phloem exudate. Undiluted preparation of phloem exudate contains $110 \pm 10 \mu \mathrm{g}$ of total proteins per $\mu \mathrm{l}$. Central panel: Effect of ionic strength on the complex formation. Monomeric transcripts of (+)HSVd RNA ( $5 \mathrm{ng}$ ) were incubated (30 min on ice) with a 1/50 dilution of phloem exudate at increasing concentrations of $\mathrm{NaCl}(0.1,0.2,0.4,0.8,1$, and $1.2 \mathrm{M}$; lanes 1-6) and treated as described in A. Lane 7: Free HSVd RNA. Right panel: Effect of temperature on the complex formation. Monomeric transcripts of (+)HSVd RNA $(5 \mathrm{ng})$ were incubated ( $30 \mathrm{~min}$ in ice) with $5 \mu \mathrm{l}$ of a $1 / 50$ dilution of phloem exudate and exposed at room temperature (lane 1), $37^{\circ} \mathrm{C}$ (lane 2), $42^{\circ} \mathrm{C}$ (lane 3), and $56^{\circ} \mathrm{C}$ (lane 4). Lane 5: Free HSVd RNA. B, Gel retardation analysis with Avocado sunblotch viroid (left panel) and Citrus exocortis viroid RNA (right panel) and different phloem exudate dilutions. Lane 1: Free RNA. Lanes $2-$ 4: RNA incubated with dilutions of $1 / 500,1 / 250$, and $1 / 50$ of the phloem exudate. Formation of the ribonucleotide complex and its analysis was carried out as described above. 
(used in the digestion procedure) and a phloem protein of low molecular weight were observed consistently in both lanes. The recovery of this differential band suggests that this 24- to $26-\mathrm{kDa}$ of protein could be involved in the formation of the ribonucleoprotein complex.

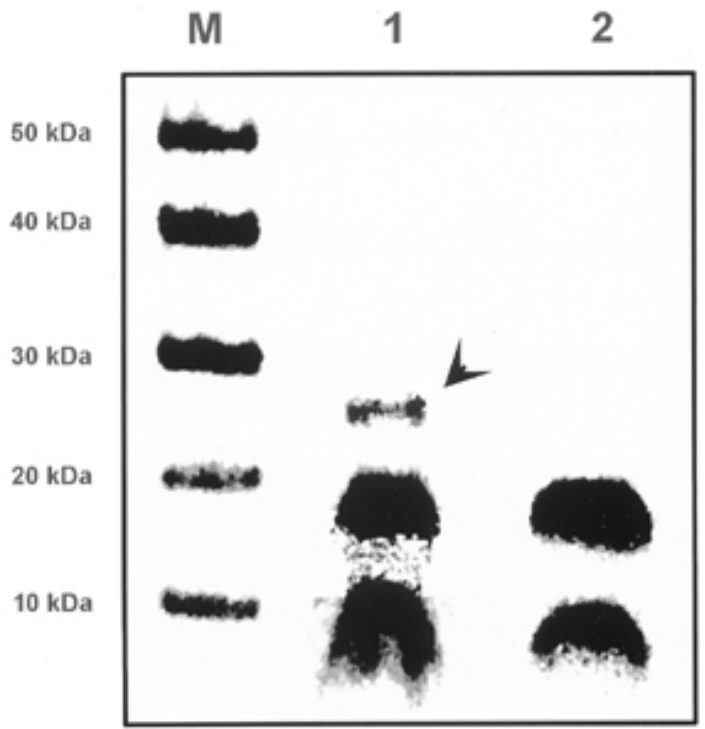

Fig. 2. Recovery of a 24-26-kDa protein from the ribonucleoprotein complex formed between Hop stunt viroid (HSVd)-RNA and phloem proteins. ${ }^{32} \mathrm{P}-$ labeled $(+) H S V d$ RNA was incubated with phloem exudate, UV crosslinked ( $3 \mathrm{~J}$ per $\left.\mathrm{cm}^{2}\right)$, and subjected to electrophoresis in a $12 \%$ polyacrylamide gel. The ribonucleoprotein complex was visualized by autoradiography of the dried gel and excised. The fragment of polyacrylamide gel containing the complex was dehydrated, digested for $2 \mathrm{~h}$ at $37^{\circ} \mathrm{C}$ with RNase- $\mathrm{T}_{1}$, and electroeluted. The electroeluted products were subjected to electrophoresis in a 15\% polyacrylamide gel and silver stained (lane 1). The same process was repeated with phloem exudate incubated without HSVd RNA (lane 2). Lane M: Molecular weight markers. The 24-26-kDa differential protein recovered is marked with an arrow.

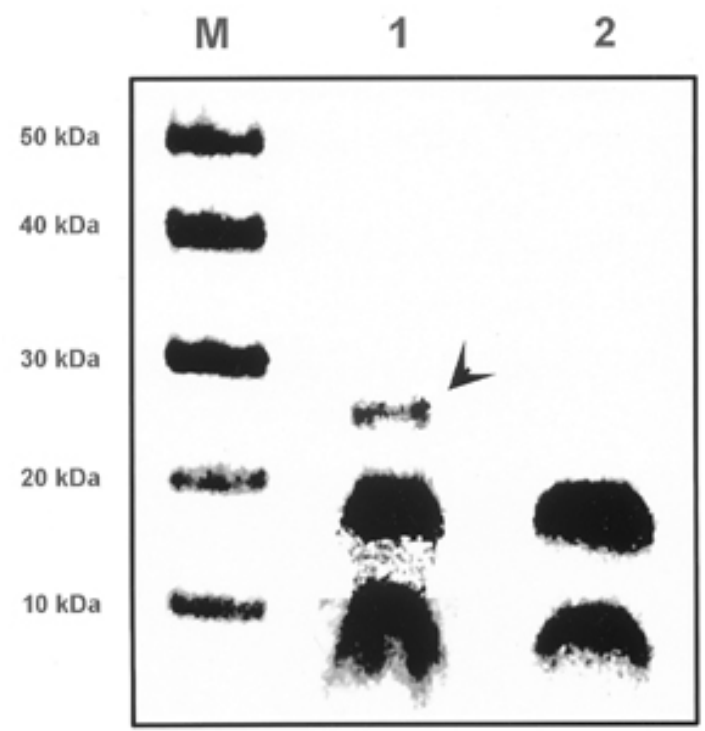

Fig. 3. Sodium dodecyl sulfate-polyacrylamide gel electrophoresis of total phloem exudate proteins of cucumber plants (lane 1) and purified PP2 (lane 2). Lane M: Molecular weight markers. The monomeric form of the PP2, the most abundant protein present in the phloem exudate of cucumber, is marked with an asterisk.
The size of the recovered protein is similar to the one described for the phloem protein 2 (PP2) from Cucurbitaceae spp. (Read and Northcote 1983a). Therefore, the phloem exudate of cucumber plants was subjected to SDS-PAGE and Coomassie blue stained, and the putative PP2 was excised and electroeluted. The recovered protein was dialyzed $24 \mathrm{~h}$ in water, vacuum concentrated, and analyzed by SDS-PAGE (Fig. $3)$. Analysis of the peptide pattern after treatment with cyanogen bromide gave strong indication that the purified protein was indeed PP2 (data not shown). Monomeric transcripts of (+)HSVd-RNA were then incubated with purified PP2 and subjected to gel retardation analysis. The electrophoretic mobility of HSVd-RNA was retarded by the purified PP2, revealing, for what we believe is the first time, the RNAbinding properties of this phloem protein (Fig. 4, lane 2).

The different electrophoretic mobility of the PP2-HSVd RNA complex versus the phloem exudate-HSVd RNA complex could be explained by the existence, in the latter case, of other phloem proteins. In this sense, it is interesting to note that previous analysis of phloem filaments in vitro indicated globular, cytoplasmic PP2 cross-links with PP1 polymers by disulphide bonds between cysteine residues (Read and Northcote 1983a). Another, more plausible explanation that could account for the faster electrophoretic mobility observed when purified PP2 is used is that, as a consequence of the purification procedure, this protein could not recover its native form and thus would have lost its cooperative properties. It is well established that, for most RNA-binding proteins, the RNAbinding capability is structure dependent ( $\mathrm{Li}$ and Palukaitis 1996). It must be stressed that the PP 2 recovered after preparative electrophoresis (Fig. 3) and used in the binding experiments (Fig. 4) is the monomeric form, and the form present within the phloem is the dimeric one (Read and Northcote 1983b). It is tempting to speculate that the cooperative properties of the protein would rely on this dimeric form.

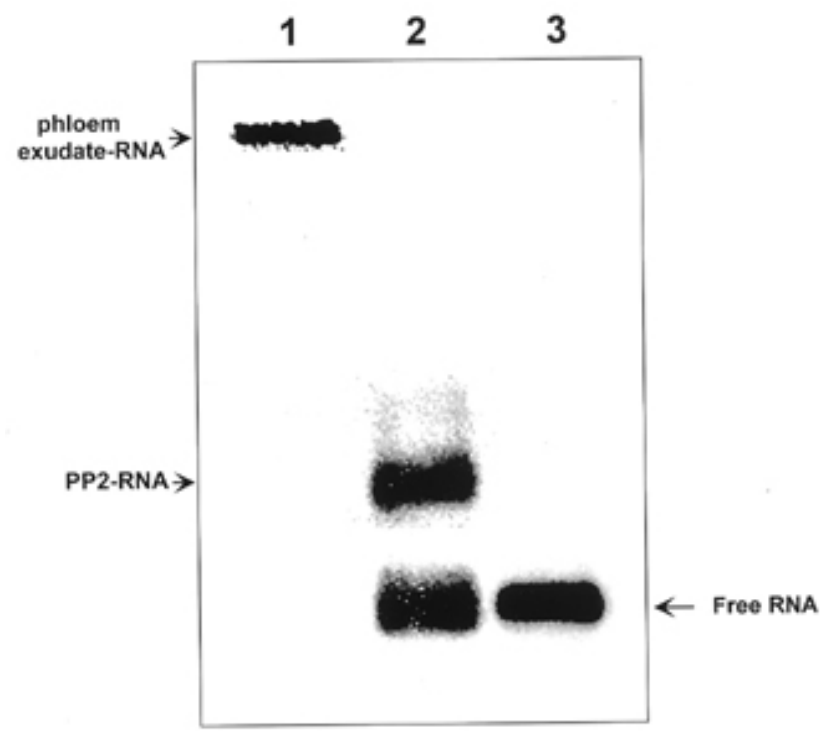

Fig. 4. RNA binding properties of the PP2 purified from cucumber phloem. Gel retardation analysis of the Hop stunt viroid (HSVd)-RNA in presence of 1/50 dilution of phloem exudate (lane 1) or $100 \mathrm{ng}$ of purified PP2 (lane 2). Lane 3: Free HSVd RNA. The formation of the ribonucleoprotein complexes and their analyses were carried out as described in Figure 1. 
Interestingly, the PP2 of the Cucurbitaceae spp. has the capacity to modify the size exclusion limit of plasmodesmata and move from cell to cell when microinjected into mesophyll cells of cucurbit cotyledons (Balachandran et al. 1997). In addition, PP2 of Cucurbita maxima has been shown to move from the companion cells, where it is synthesized, into sieve tubes (Golecki et al. 1999) and to translocate in intergeneric grafts within the assimilate stream toward sink tissues (Fisher et al. 1992; Golecki et al. 1998; Golecki et al. 1999). These previous observations, together with the RNA-binding properties shown here, make this protein a likely candidate to be involved in the translocation of plant RNAs in the phloem, although further experiments are necessary to demonstrate this unequivocally.

\section{ACKNOWLEDGMENTS}

This work was supported partially by grant BIO99-0854 from the Spanish granting agency DGICYT. We thank C. Hernández, J. A. Daròs, and P. Más for their valuable comments and critical reading of the manuscript, and R. Flores for the facilities provided during the realization of this work. G. Gómez was the recipient of a fellowship from CONICET of Argentina.

\section{LITERATURE CITED}

Astruc, N., Marcos, J., Macquaire, G., Candresse, T., and Pallás, V. 1996. Studies on the diagnosis of Hop stunt viroid in fruit trees: Identification of new hosts and application of a nucleic acid extraction procedure based on non-organic solvents. Eur. J. Plant Pathol. 102:837-846.

Balachandran, S., Xiang, Y., Schobert, C., Thompson, G., and Lucas, W. 1997. Phloem sap proteins from Cucurbita maxima and Ricinus communis have the capacity to traffic cell to cell through plasmodesmata. Proc. Natl. Acad. Sci. USA 94:14150-14155.

Carey, J. 1991. Gel retardation. Pages 103-117 in: Methods in Enzymology: Protein-DNA Interactions, Vol. 208. R. T. Sauer, ed. Academic Press, San Diego, CA, U.S.A.

Citovsky, V., and Zambryski, P. 2000. Systemic transport of RNA in plants. Trends Plant Sci. 5:52-54.

Diener, T. O. 1991. Subviral pathogens of plants: Viroids and viroid-like satellites RNAs. FASEB J. 5:2808.2813.

Ding, B., Kwon, M.-O., Hammond, R., and Owens, R. 1997. Cell to cell movement of potato spindle tuber viroid. Plant J. 12:931-936.
Esau K., and Cronshaw, J. 1967. Tubular components in cells of healthy and tobacco mosaic virus-infected Nicotiana. Virology 33:26-35.

Eschrich, W., Evert, R. F., and Heyer, W. 1973. Proteins of sieve tube exudate of Cucurbita maxima. Planta 100:208-221.

Fisher, D., Wu, Y., and Ku, M. 1992. Turnover of soluble proteins in the wheat sieve tube. Plant Physiol. 100:1433-1441.

Flores, R., Diserio, F., and Hernández, C. 1997. Viroids: The noncoding genomes. Semin. Virol. 8:65-73.

Golecki, B., Schulz, A., Carsten-Behrens, U., and Kollman, R. 1998. Evidence of graft transmission of structural phloem proteins or their precursors in heterografts of Cucurbitaceae. Planta 206:630-640.

Golecki, B., Schulz, A., and Thompson, G. 1999. Translocation of structural $\mathrm{P}$ proteins in the phloem. Plant Cell 11:127-149.

Jorgensen, R., Atkinson, R., Forster, R., and Lucas, W. 1998. An RNA based information superhighway in plants. Science 279:1417-1596.

Li, Q., and Palukaitis, P. 1996. Comparison of the nucleic acid- and NTP-binding properties of the movement protein of cucumber mosaic cucumovirus and tobacco mosaic tobamovirus. Virology 216:71-79.

Lucas, W., and Wolf, S. 1999. Connection between virus movement, macromolecular signalling and assimilate allocation. Curr. Opin. Plant Biol. 2:192-197.

Marcos, J. F., Vilar, M., Perez-Paya, E,. and Pallás, V. 1999. In vivo detection, RNA-binding properties and characterisation of the RNAbinding domain of the putative movement protein from carnation mottle carmovirus (CarMV). Virology 255:354-365.

Palauqui, J., Elmayan, T., Pollien, J., and Vaucheret, J. 1997. Systemic acquired silencing: Transgene-specific post-transcriptional silencing is transmitted by grafting from silenced stocks to non-silenced scions. EMBO J. 16:4738-4745.

Pallás, V., Navarro, A., and Flores, R. 1987. Isolation of a viroid-like RNA from hop different from Hop stunt viroid. J. Gen. Virol. 68:3201-3205.

Pallás, V., Más, P., and Sánchez-Navarro, J. 1998. Detection of plant RNA viruses by non-isotopic dot-blot hybridization. Pages 471-478 in: Plant Virus Protocols: From Virus Isolation to Transgenic Resistance. G. Foster and S. Taylor, eds. Humana Press, Totowa, NJ, U.S.A.

Palukaitis, P. 1987. Potato spindle tuber viroid: Investigation of longdistance intra-plant transport route. Virology 158:239-241.

Read, S., and Northcote, D. 1983a. Chemical and immunological similarities between the phloem proteins of three genera of Cucurbitaceae. Planta 158:119-127.

Read, S., and Northcote, D. 1983b. Subunit structure and interactions of the phloem proteins of Cucurbita maxima. Eur. J. Biochem. 134:561-569.

Thompson, G., and Schulz, A. 1999. Macromolecular trafficking in the phloem. Trends Plant Sci. 4:354-360.

Xoconostle-Cazares, B., Xiang, Y., Ruíz-Medrano, R., Wang, H., Monzer, J., Yoo, B., McFarland, C., Franceschi, V., and Lucas, W. 1999. Plant paralog to viral movement protein that potentiates transport of mRNA in the phloem. Science 238:94-98. 